Research Article

\title{
A Study on the Sloshing Problem of Vertical Storage Tanks under the Action of Near-Fault Earthquakes
}

\author{
Lijian Zhou, ${ }^{1}$ Tian Xu $\mathbb{D}^{1},{ }^{1}$ Zhaohong Lu $\mathbb{D}^{1,2}$ and Dong Zhang ${ }^{2}$ \\ ${ }^{1}$ Northeast Petroleum University, Daqing, China \\ ${ }^{2}$ CNPC Key Laboratory of Oil \& Gas Storage and Transportation, PetroChina Pipeline R\&D Center, Langfang, China
}

Correspondence should be addressed to Zhaohong Lu; luzh2008@126.com

Received 30 July 2019; Revised 4 December 2019; Accepted 2 January 2020; Published 22 January 2020

Guest Editor: Jingfeng Yuan

Copyright (c) 2020 Lijian Zhou et al. This is an open access article distributed under the Creative Commons Attribution License, which permits unrestricted use, distribution, and reproduction in any medium, provided the original work is properly cited.

In this study, through a vibration table test, finite element simulation, and research on the rationality of the wave-height fortification of national storage tank specifications, the sloshing response of vertical storage tanks under the action of near-fault ground motion was analyzed. The test results showed that the sloshing wave height of a vertical storage tank was larger under nearfault or long-period ground motions, and the relationship between the sloshing wave height and the peak acceleration of input ground motions was approximately linear. The numerical simulations of the model tank showed that the simulation wave height and the test wave-height data were well fitted. Therefore, it was feasible to simulate the sloshing of large vertical storage tanks using ADINA software. In addition, a large number of sloshing simulations of near-fault ground motions on $10,000 \mathrm{~m}^{3}$ vertical storage tanks were performed. The simulated wave height had a high correlation with the predominant period or pulse period of near-fault ground motions. Under the calculation with similar parameters, the wave height of the tank standard in several countries had a lower fortification of the near-fault excitation wave height. Through the root mean-square method using a small sample size, a wave-height correction under a near-fault effect was applied to the wave-height formula for the Chinese tank seismic specification. Finally, the problem of a double-damping correction was addressed by adjusting China's GB50341 wave-height formula. This work provides a reference value for practical engineering applications.

\section{Introduction}

Large vertical storage tanks have thin tank walls and hold a large volume, and the basic self-vibration period of the liquid storage is long. Under the action of long-period ground motion, liquid storage produces a large nonlinear sway, and the huge force easily causes damage to the filling roof and buckling of the tank wall $[1,2]$. For example, in the 1980s, the earthquake in the middle of the Sea of Japan caused damage to oil tanks with a shaking period of about $10 \mathrm{~s}$ in the nearby city of Niigata and caused a fire [3]. Then in 1991, the 6.9 magnitude earthquake in Costa Rica caused overturning and instability of storage tanks in local steel plants, which caused huge losses [4].

With the increasing demand for large vertical tanks in various countries of the world, their role in the development of the economy and petrochemical industry is becoming increasingly important. Many scholars have conducted research on tank sloshing. Yan [3] conducted three-dimensional shaking table tests on a vertical open tank and a floating roof tank. Through the input of different amplitudes and frequency of ground motion, the data of tank sloshing wave height and displacement were obtained. Wang et al. [5] simulated three kinds of tanks with different liquid levels under earthquake conditions using ADINA software and analyzed the wave height of liquid sloshing, peak acceleration of the tank wall, and hydrodynamic pressure. Cheng et al. [6] studied the sloshing response of liquid in a rigid cylindrical tank with a rigid annual baffle uncle. The problem of a shaking response under near-fault ground motion, however, was not involved. Near-fault ground motions have large velocity pulses and abundant long-period waveforms, which are liable for producing double resonance with storage tanks, resulting in large-scale sloshing of storage 
fluid and potential hazards to storage tanks and the surrounding environment [7]. Moreover, because China is located between the Pacific Rim Seismic Zone and the Himalayan Seismic Zone, near-fault earthquakes often occur in China. Therefore, this article studied the sloshing effect of near-fault ground motions with different spectral characteristics under excitation. On the basis of a comparison of the shaking table test, numerical simulation, and the wave-height formula of the national tank standard, we corrected the Chinese version of the wave height under near-fault ground motion to study the sloshing effect. This study provides a reference for the wave-height design of vertical storage tanks under the action of near-fault ground motion.

\section{Shaking Table Test of Vertical Storage Tank}

Seismic waves are not only complex in the frequency domain but also complex in the time domain. Therefore, it is not enough to rely solely on national codes and simulation calculations to fully reflect the response of structures to real earthquakes over time. The shaking table test is the most effective method to verify theoretical calculations and simulation calculations at present, so the engineering community often uses the shaking table test to examine the response superposition problem of a structure under the action of ground motion [8]. We selected a $1000 \mathrm{~m}^{3}$ vertical storage tank and subjected the prototype can to quarter-scale processing. According to the similarity relationship, we designed the model tank and adjusted the input ground motion parameters [1]. To study the relationship between the sloshing wave height and the seismic spectrum characteristics and the acceleration peak, we extracted the waveheight data by unidirectional seismic loading. Finally, we verified the sway simulation using the finite element software ADINA.

2.1. Test Layout and Seismic Wave Input. The geometric dimensions of the test model tank were as follows: the tank height was $2.65 \mathrm{~m}$, the tank diameter was $2.9 \mathrm{~m}$, and the liquid storage height was $2.38 \mathrm{~m}$. The arrangement of the experimental wave-height displacement meter was $0 \mathrm{~mm}$, $560 \mathrm{~mm}$, and $1300 \mathrm{~mm}$ from the center of the liquid surface, and the table-top output acceleration collector was arranged on the table below the ring beam. The tank layout is shown in Figure 1.

In this test, we selected EL-Centro wave, TCU089 wave, JM wave, and Pasadena for the input of the shaking table because of the limitation of the displacement of the table. These four waves are commonly used in the world, among which TCU089 is used for near-fault ground motion. We assigned each displacement wave a corresponding $0.05 \mathrm{~g}$, $0.1 \mathrm{~g}, 0.15 \mathrm{~g}, 0.2 \mathrm{~g}, 0.25 \mathrm{~g}, 0.3 \mathrm{~g}, 0.35 \mathrm{~g}$, and $0.4 \mathrm{~g}$ peak acceleration and derived the time similarity ratio based on the model's similarity ratio. We finally determined the time interval of each seismic wave to be $0.024 \mathrm{~s}$. Figure 2 shows the displacement time history curve of each seismic wave of $0.4 \mathrm{~g}$.
2.2. Test Data Analysis. By extracting the maximum acceleration recorded by the acceleration collector installed on the platform and comparing it with the peak acceleration of each input seismic wave, the acceleration transmitted from the vibration table to the foundation can be truly and accurately reflected. The comparison data are shown in Figure 3.

As shown in Figure 3, the difference between the output acceleration extremum and the peak value of the input acceleration is not exactly the same because the slight deviations between the input and output acceleration of seismic wave are inevitable in engineering tests. Thus, the test output data are reasonable.

We extracted the wave height corresponding to each seismic wave at different acceleration peaks, as shown in Table 1, and made a trend relationship diagram between the wave height and the corresponding acceleration peak, as shown in Figure 4.

Using Fourier transform for each of acceleration waves collected on the platform, we obtained the predominant periods of the EL-Centro wave, TCU wave, Jinmen seismic wave, and Pasadena wave, which were $0.163 \mathrm{~s}, 0.204 \mathrm{~s}, 0.28 \mathrm{~s}$, and $0.463 \mathrm{~s}$, respectively. As shown in Table 1, there were differences in the excitation wave heights of different ground motions. The excitation wave height of the excellent period was short, and the excitation wave height of the EL-Centro wave and the Golden Gate wave, whose long-period waveforms were lower, was relatively low. Conversely, the long-period waveform was rich, and the period of the nearfault ground motion TCU and Pasadena waves was relatively large. Therefore, the sloshing wave height of the vertical storage tank under the earthquake had a significant correlation with the spectral characteristics of ground motion, in particular, because the wave-height sloshing under the action of long-period ground motion cannot be ignored. It is evident from Figure 4 that as the input ground motion peak increased, the excitation wave height and the input acceleration peak increased linearly. Notably, the linear relationship between the near-fault TCU wave and the Pasadena wave with more long-term characteristics was more obvious. The ratio of any two wave heights was approximately equal to the ratio of the two acceleration peaks.

2.3. Numerical Simulation Analysis of Model Cans. We numerically simulated the model cans using the ADINA software. The purpose of the numerical simulation was to verify each simulation with the test and to verify the reliability of the finite element sloshing analysis while also comparing the differences. We based the physical properties of the numerical simulation materials on experimental measurements. The tank-sloshing simulation used the potential flow module, the tank foundation used the solid unit, and the base and tank contact surfaces adopted the contact unit. The tank model and the contact model are shown in Figure 5. The vertical tank wall and tank bottom plate selected the four-node shell unit, the foundation adopted an eight-node solid unit (3-dsold) for simulation, the liquid storage adopted an eight-node three-dimensional fluid unit, 

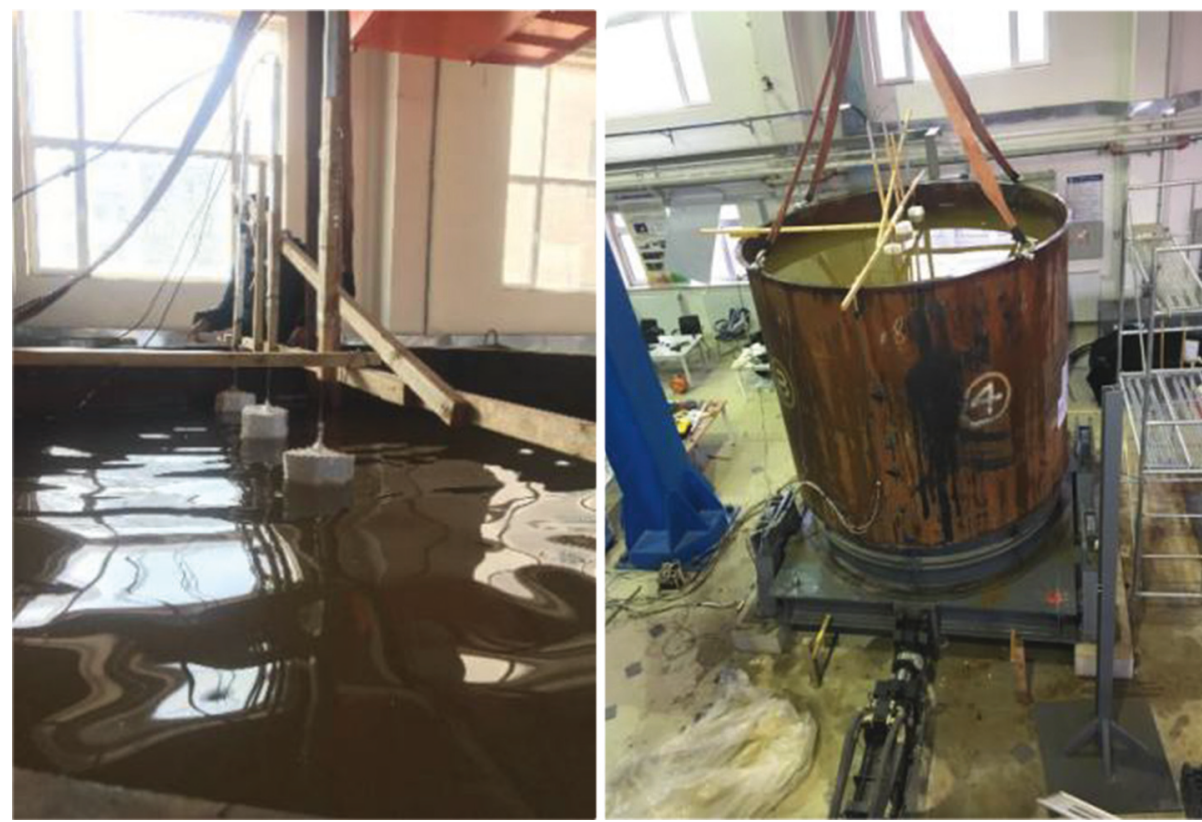

Figure 1: Test layout.

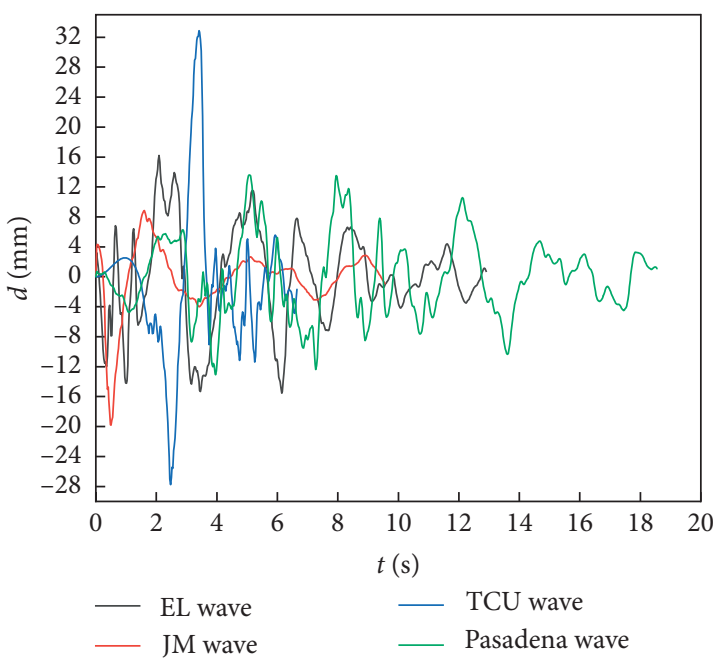

FIgURE 2: Seismic wave displacement time history diagram.

the upper surface of the liquid storage was set as the free liquid level, and the other surface was the fluid unit. ADINA automatically identified the coupling contact surface when potential flow theory was adopted, thus greatly improving the calculation speed.

The finite element model ground motion input used the accelerometer wave collected by the test bench accelerometer with a $0.3 \mathrm{~g}$ peak. We conducted a dynamic time history analysis for each seismic wave of the model. The collected sloshing wave height and the extreme value of the test wave height are shown in Table 2. Figure 6 compares the real time history curve and the test time history curve of the waveheight extreme point.

Table 2 shows that the simulated wave height and the test wave-height sway extreme values are similar. The average

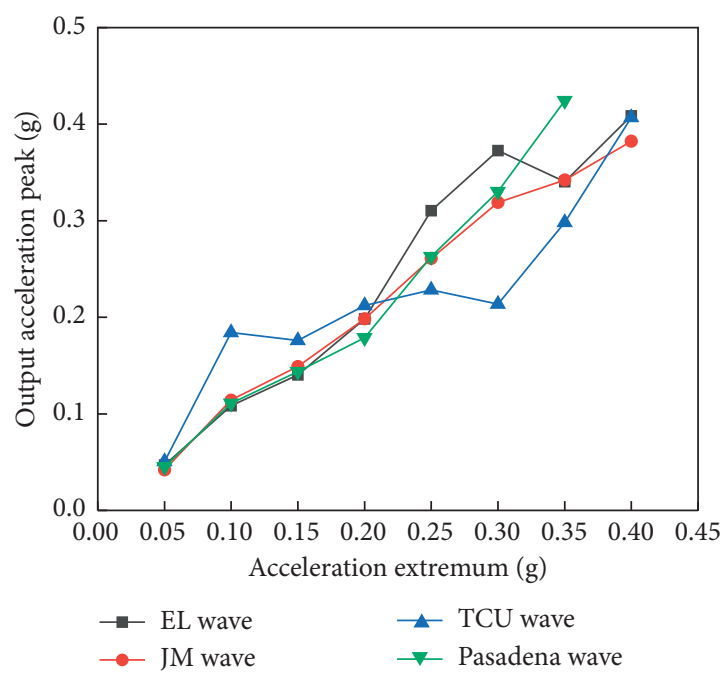

Figure 3: Table-top output acceleration peak. Note. Pasadena wave with an extremum acceleration of $0.4 \mathrm{~g}$ exceeds the mesa displacement.

difference rate was $12.7 \%$, and the simulated wave height was slightly larger than the test wave height, which also was related to the wave-height acquisition device. Because the elastic displacement meter had a suppression effect on the sloshing wave height, the test wave height was slightly smaller than the simulated wave height. Figure 6 shows that the simulation and experimental extreme wave-height time history curves were basically the same-only the waveheight value was slightly different. From the four waveheight time history comparison curves, the simulation and test data were basically the same, and both were mutually verified. Thus, it was feasible to use the finite element software ADINA to simulate vertical tank sloshing. 
TABLE 1: Test sloshing wave height (in millimeters).

\begin{tabular}{|c|c|c|c|c|c|c|c|c|}
\hline Seismic wave & $0.05 \mathrm{~g}$ & $0.1 \mathrm{~g}$ & $0.15 \mathrm{~g}$ & $0.2 \mathrm{~g}$ & $0.25 \mathrm{~g}$ & $0.3 \mathrm{~g}$ & $0.35 \mathrm{~g}$ & $0.4 \mathrm{~g}$ \\
\hline EL-Centro wave & 11.167 & 25.813 & 34.787 & 47.076 & 57.967 & 53.161 & 68.742 & 88.73 \\
\hline JM wave & 14.064 & 14.59 & 20.36 & 27.25 & 37.35 & 43.26 & 53.52 & 61.1 \\
\hline TCU wave & 15.9 & 31.46 & 50.11 & 64.506 & 79.92 & 92.49 & 115.6 & 120.2 \\
\hline Pasadena wave & 11.4 & 18.62 & 33.54 & 59.17 & 101.6 & 126.3 & 149.26 & \\
\hline
\end{tabular}

Note. Pasadena wave with an extremum acceleration of $0.4 \mathrm{~g}$ exceeds the mesa displacement.

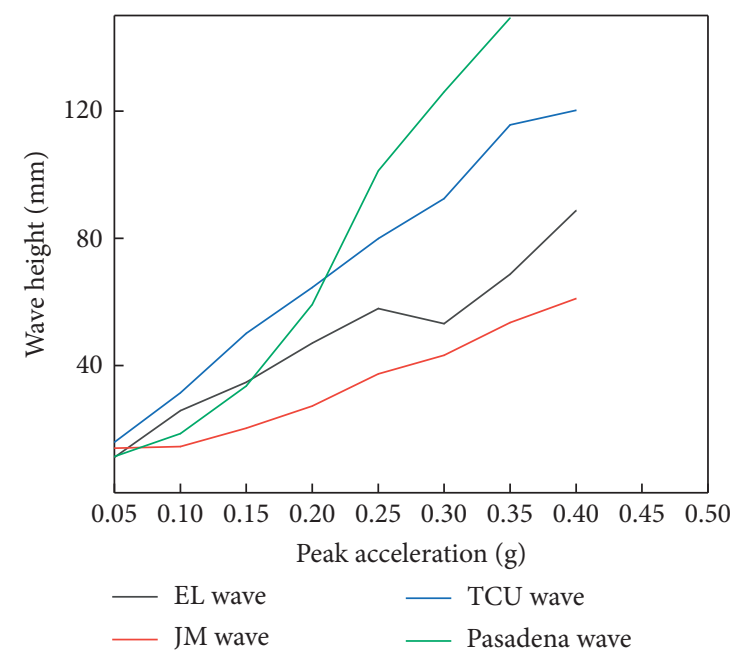

FIgURE 4: Wave height and peak acceleration trend graph.

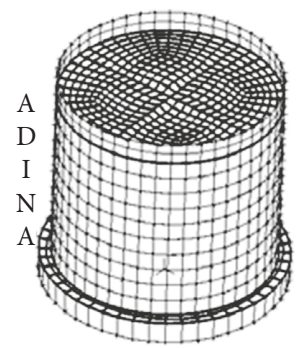

(a)

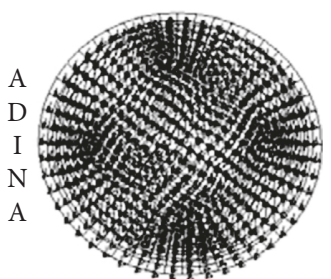

(b)

FIgURE 5: Finite element model of storage tank. (a) Tank model. (b) Contact model.

TABLE 2: Simulation and test wave heights (in millmeters).

\begin{tabular}{lccccccc}
\hline \multirow{2}{*}{ Seismic wave } & \multicolumn{2}{c}{ EI-Centro wave } & \multicolumn{2}{c}{ JM wave } & \multicolumn{2}{c}{ TCU wave } & \multicolumn{2}{c}{ Pasadena wave } \\
& “_” & “+” & “_” & “+” & “_” & “+” & “-” \\
\hline Simulation wave height & 39 & 51 & 32 & 28 & 59.6 & 50.5 & 76.1 \\
Test wave height & 46.9 & 47.1 & 27 & 27.3 & 38.8 & 59.17 & 50.6 \\
Difference rate (\%) & 16.8 & 8.2 & 18.5 & 2.5 & 54 & 14.6 & 50.3 \\
\hline
\end{tabular}

Note. "+" and "-_ correspond to the extreme peak and trough of wave height, respectively.

\section{Finite Element Analysis of Vertical Storage Tanks and Correction of Chinese Standard Wave-Height Formula}

From the analysis of the test results, we determined that the sloshing wave height of the vertical storage tank was related to the spectral characteristics of the ground motion. The richer the long-period waveform, the higher the excitation wave height. This was especially true for the near-fault ground motion, which often contained a large number of long-period seismic waveforms, and the excitation wave height was large. Because of the large-scale pulse of near-fault ground motion, the excitation displacement of the structure was large, and the ultimate displacement of the vibration table was small. This 


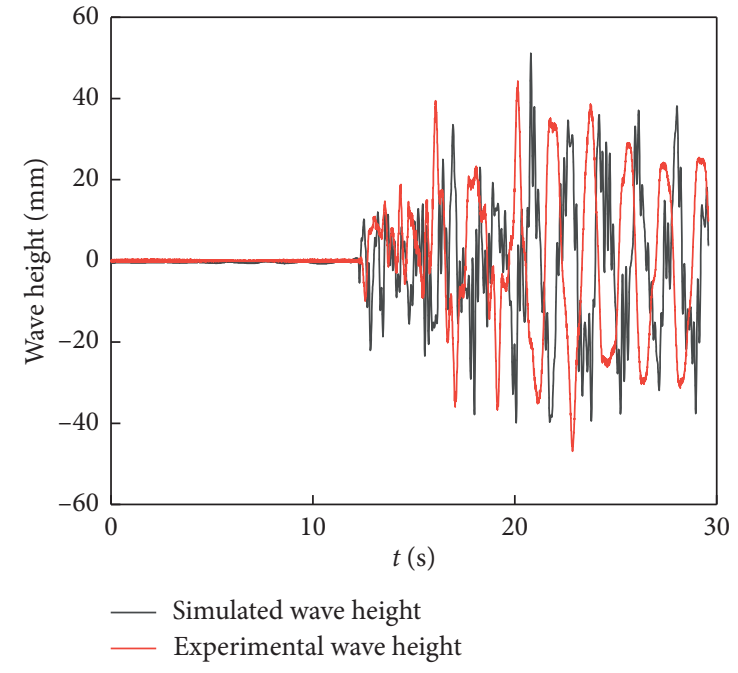

(a)

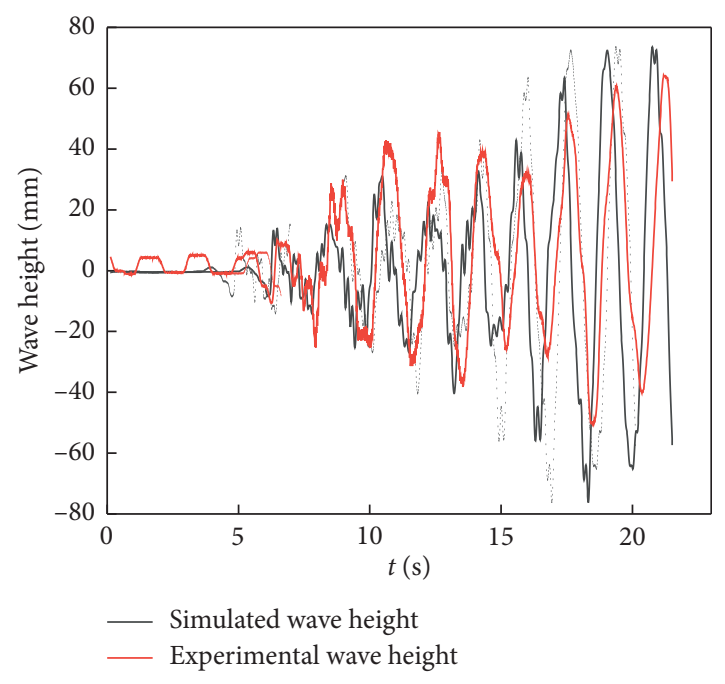

(c)

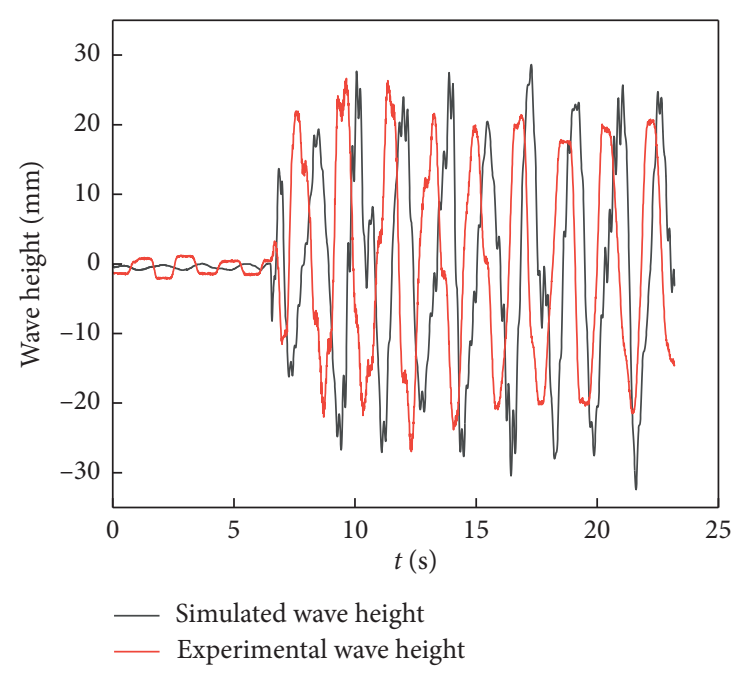

(b)

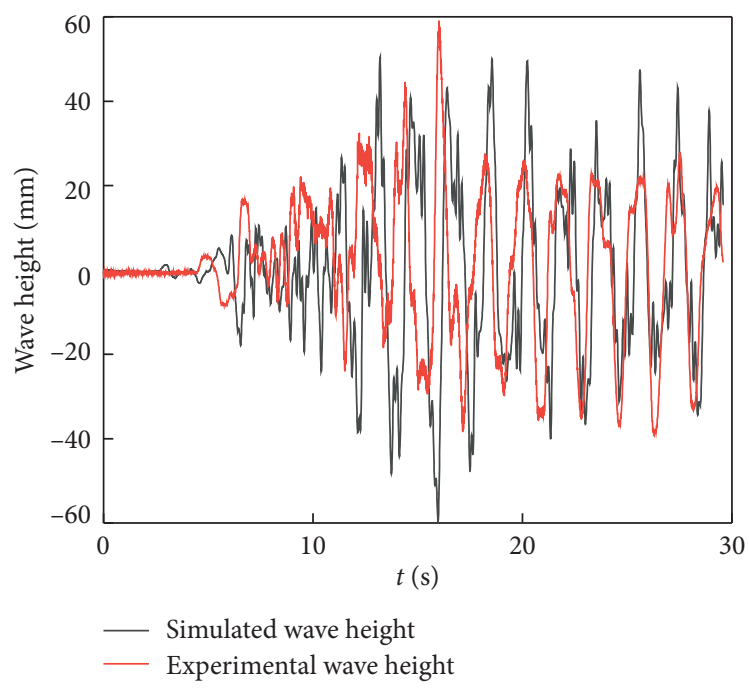

(d)

FIGURE 6: Comparison of simulated wave-height and test wave-height time history curves. (a) EL-Centro time history curve of the wave. (b) JM time history curve of the wave. (c) Taft time history curve of the wave. (d) Pasadena time history curve of the wave. Note. When the duration time of ground motion stopped, the storage fluid will turn into free vibration. The damping ratio of the storage fluid is 0.005 . So there will be a attenuation trend after the shaking wave height of the storage fluid in the figure.

limited the output of the near-fault ground motion to the structural displacement. The engineering community often uses numerical analysis because this method can be used to explore the sloshing effect of large vertical storage tanks under near-fault ground motion. Therefore, in this part of the test, we selected a $10,000 \mathrm{~m}^{3}$ vertical storage tank for numerical simulation under near-fault ground motion to explore the correlation between excitation wave height and the predominant period and pulse period. We also examined the high envelope of the excitation wave of the near-fault ground motion. We corrected the wave-height formula of the seismic specification of the Chinese tank for near-fault ground motion.

\subsection{Numerical Simulation of $10,000 \mathrm{~m}^{3}$ Vertical Tank Sloshing.} The basic dimensions of the $10,000 \mathrm{~m}^{3}$ vertical storage tank were as follows: tank height was $17.5 \mathrm{~m}$, diameter was
$28.3 \mathrm{~m}$, and liquid storage height was $14 \mathrm{~m}$. The finite element model and the first-order mode with a period of $5.42 \mathrm{~s}$ are shown in Figure 7. The selection of seismic waves was based on three elements of ground motion, namely, ground motion duration, spectral characteristics, and effective peaks. From the Pacific Earthquake Engineering Research Center (PEER), we selected 38 near-fault ground motions recorded worldwide. Using the potential flow theory of the finite element software ADINA, we input the $0.2 \mathrm{~g}$ near-fault ground motion into the storage tank and used the dynamic time-integration method to calculate the sloshing wave height of the storage tank. Table 3 gives the excitation wave height and period parameters of the 38 near-fault ground motions.

As can be seen in Table 3, different seismic waves have different wave heights. Because different ground motions have different frequency characteristics, the wave heights are 


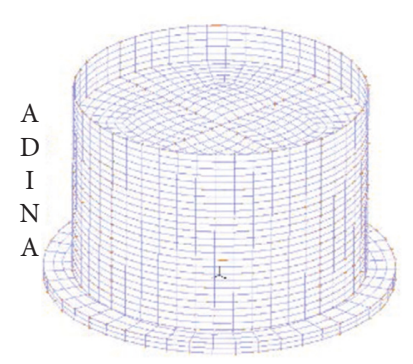

(a)

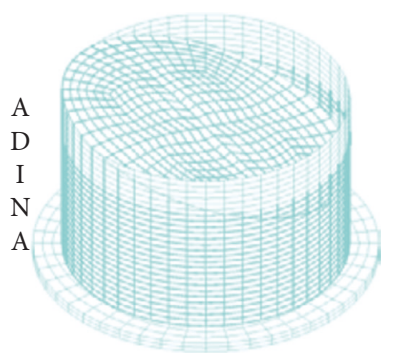

(b)

FIgURE 7: 10,000 $\mathrm{m}^{3}$ finite element model and first-order model. (a) Finite element model. (b) First-order mode.

TABLe 3: Spectrum parameters and excitation wave heights of near-fault ground motions.

\begin{tabular}{|c|c|c|c|c|c|c|c|c|c|}
\hline $\begin{array}{l}\text { Seismic } \\
\text { wave }\end{array}$ & $\begin{array}{l}\text { Wave height } \\
(\mathrm{mm})\end{array}$ & $\begin{array}{c}\text { Seismic } \\
\text { wave }\end{array}$ & $\begin{array}{l}\text { Wave height } \\
(\mathrm{mm})\end{array}$ & $\begin{array}{c}\text { Seismic } \\
\text { wave }\end{array}$ & $\begin{array}{l}\text { Wave height } \\
(\mathrm{mm})\end{array}$ & $\begin{array}{c}\text { Seismic } \\
\text { wave }\end{array}$ & $\begin{array}{l}\text { Wave height } \\
(\mathrm{mm})\end{array}$ & $\begin{array}{c}\text { Seismic } \\
\text { wave }\end{array}$ & $\begin{array}{l}\text { Wave height } \\
(\mathrm{mm})\end{array}$ \\
\hline RSN1496 & 1880 & RSN180 & 558 & RSN1244 & 1409 & RSN1511 & 1445 & RSN176 & 870 \\
\hline RSN147 & 173 & RSN182 & 776 & RSN1475 & 1854 & RSN1519 & 1581 & RSN6911 & 1448 \\
\hline RSN159 & 499 & RSN285 & 1028 & RSN1476 & 240 & RSN1528 & 1752 & RSN6927 & 1926 \\
\hline RSN170 & 1449 & RSN900 & 1507 & RSN1478 & 3410 & RSN1531 & 4548 & RSN185 & 1383 \\
\hline RSN171 & 661 & RSN1085 & 448 & RSN1486 & 1789 & RSN6887 & 1859 & RSN8119 & 843.3 \\
\hline RSN173 & 2300 & RSN1161 & 1116 & RSN1503 & 1837 & RSN6897 & 1823 & RSN8606 & 3090 \\
\hline RSN1165 & 888 & RSN1505 & 1724 & RSN6906 & 1483 & RSN6942 & 1510 & RSN6962 & 2797 \\
\hline RSN6959 & 1734 & RSN6969 & 4626 & RSN1489 & 970 & & & & \\
\hline
\end{tabular}

Note. RSN is coded by Pacific Seismic Engineering Research Center (PEER).

different. The experiments showed that the excitation wave height had a certain correlation with the spectral characteristics of ground motion. Therefore, we studied the nearfault ground motion predominant period and the trend of pulse period and wave height to explore the correlation between wave height and ground motion period parameters. The trend chart is shown in Figure 8.

As shown in Figure 8, the use of the near-fault predominant cycle and pulse period to characterize wave height contributed to certain tendencies. Large wave-height values were concentrated mainly near the first-order sloshing cycle, and the larger the waveform period, the larger the excitation wave height. We used the Pearson correlation coefficient to measure the correlation between the predominant period and the pulse period and excitation wave height, and the calculated correlation coefficients were 0.495 and 0.458 , respectively. Both exhibited a moderate degree of correlation. The predominant period was slightly higher than the correlation of the pulse period and wave height. Therefore, it was reasonable to use the predominant period and pulse period of the near-fault ground motion to characterize the excitation wave height.

3.2. Comparative Analysis of Incentive Wave Height of NearFault Ground Motion and Wave Height of Storage Tanks in Different Countries. Although the seismic specifications of the Sino-U.S. European and Japanese storage tanks differed in terms of seismic concept, design level, and definition of ground motion parameters, the design of the sloshing was similar. The sloshing cycle of the four countries' specifications was a first-order sloshing cycle that was quoted from the Housner [9] rigid tank wall. The sloshing wave-height formula was also based on the rigid tank wall to consider the two-point or three-mass theoretical model of the elastic tank wall [10], and we applied this formula to the sloshing formula of each country's response spectrum. National normative sloshing wave heights and period formula are shown in Table 4 . We used 8 degrees 0.2 g ground basic acceleration, class III site, and seismic grouping for the first group of seismic design parameters for China's $10,000 \mathrm{~m}^{3}$ standard wave-height formula. Finally, according to the research results of Hui, Li, Zhinan, and others [11-13], and through a comparison and analysis of national norms, we selected the seismic design parameters with similar specifications in foreign countries to calculate the sloshing period and wave height. The calculated results are compared with the simulated wave height of near-fault ground motion. The distribution diagram of simulated wave height of near-fault ground motion is shown in Figure 9.

The calculated wave heights in China, United States, Europe, and Japan are basically within $1500 \mathrm{~mm}$. Among them, Chinese code GB50761 is $1067 \mathrm{~mm}$, American code API650 is $1465 \mathrm{~mm}$, European code BS EN8-4 is $426 \mathrm{~mm}$, and Japanese code JIS B850 is $1372 \mathrm{~mm}$. From the simulated wave height distribution of near-fault ground motion in Figure 9, it can be seen that the specifications cannot fully envelop the excitation wave height of the near-fault ground motion. The European standard calculation wave height was lower than most of the excitation wave heights and was 10 times smaller than the individual seismic excitation wave. From the mean effect, we determined that the average wave height of 38 ground motions was $1611 \mathrm{~mm}$, which was 1.51 


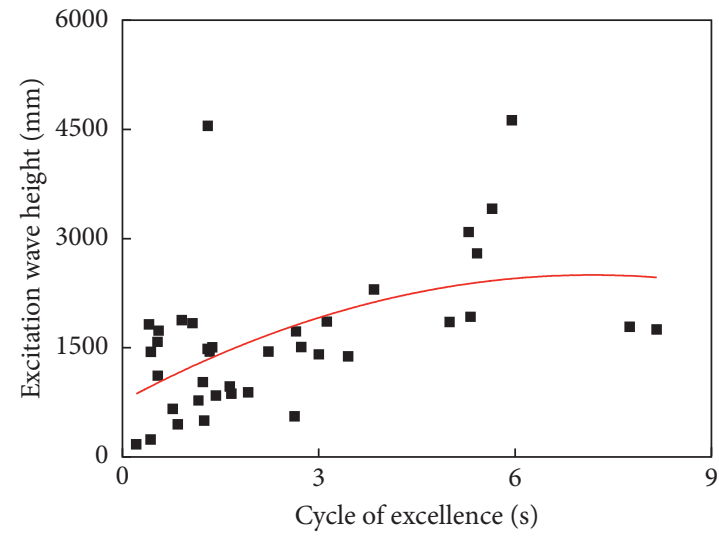

(a)

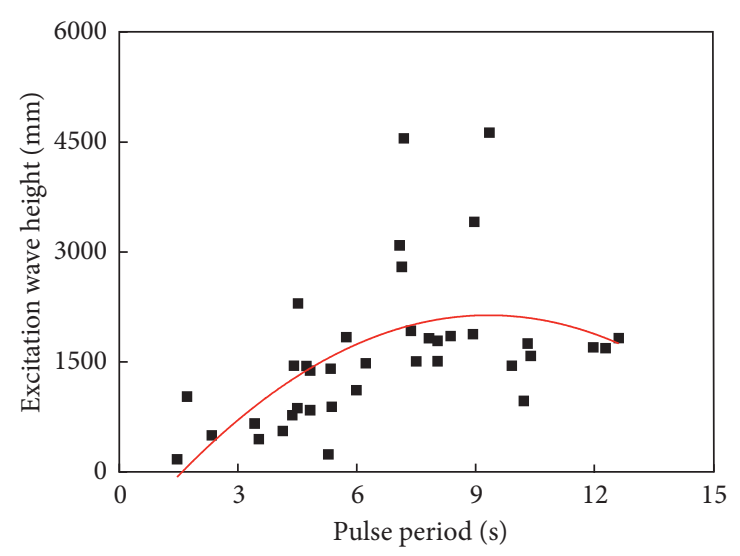

(b)

FIGURE 8: Spectrum parameters of near-fault ground motion and wave height scatter plot. (a) Trend map of predominant period and wave height. (b) Trend chart of pulse period and wave height.

times that of the calculated wave height of China's standard GB50761, 1.1 times that of the US standard, 3.78 times that of the European standard, and 1.21 times that of the Japanese standard wave height. From this, we also concluded that it is unreasonable for countries to standardize the fortification of high-period waveforms with near-fault ground motion excitation wave heights, and it was necessary to correct the wave height of near-fault ground motion for normal waves.

\subsection{Wave-Height Correction of China's Tank Specification.} Excessive wave height under the action of ground motion will cause the "stuck" of the floating roof or the buckling of the dome. In the norm of API 650, GB 50341, or GB 50761, the calculation of the base shear force, base bending moment, and the stress of the tank wall of each layer did not consider the influence of the sloshing wave height. They only specify the reserved height from the liquid storage surface to the tank top. So it is necessary for designers to consider the effect of shaking wave height on the tank under the seismic action with large excitation wave height. In order to reasonably set up defenses of the wave height of near-fault ground motions, this article will propose a long-period correction of the Chinese standard wave height formula using the root-mean-square method.

The root mean square (RMS) represented the effective value of a set of discrete data (formula (1)). Compared with the mean value of data, RMS better represented the confidence value of discrete data. We took 38 near-fault ground motion excitation wave heights, used RMS to calculate the effective value of this set of discrete data, and corrected the wave height according to the ratio of the effective value and the normative wave-height value. We processed the mean square root and mean values of the excitation wave heights of 38 near-fault seismic waves for $10,000-\mathrm{m}^{3}$ vertical storage tanks. The calculated data are shown in Table 5:

$$
X_{\mathrm{rms}}=\sqrt{\frac{\sum_{i=1}^{N} X_{i}^{2}}{N}}=\sqrt{\frac{X_{1}^{2}+X_{2}^{2}+\cdots+X_{N}^{2}}{N}},
$$

where $X_{i}$ denotes the value of elements in the sample and $N$ denotes the total amount of samples.

Table 5 shows that the RMD value was larger than the average value because the RMS value had a larger confidence interval for a group of data than the average value, which was more representative of the effective value of a set of discrete data. The RMS value was larger than the normative waveheight value of the weak site calculated using China's two norms. Because GB50341 repeatedly considered the damping correction, its calculated wave height was larger, but it was still less than the effective value of the sample wave height.

We applied the formula $h_{v}=0.837 \mathrm{Ra}$ to the sloshing wave height of GB50341, which was derived from the potential flow theory and considered the fluid viscosity. We referred to the 0.005 damping ratio correction for such countries as Japan and the United States, which was multiplied by a factor of 1.79 . When the earthquake impact coefficient $a$ was calculated, the relevant parameters were still calculated using the damping ratio of 0.005 , so we considered the double-damping correction. The wave-height formula of GB50761, however, considered the singledamping correction. Therefore, when we calculated the wave-height correction of GB50341 by statistical RMS value, we performed a single-damping correction and considered only the damping correction when calculating the seismic influence coefficient. We simulated wave height by ground shaking with a small sample size of a specific tank type and used the ratio of effective value to normal value to correct the wave height under near-fault ground motion. This value can be used for practical engineering. For other types of tanks, this method can also be used to make small sample capacity comparison, get the RMS value for correction, and calculate the conservative wave height for design. The correction formula is as follows:

GB50341-2014, Code for Design of Vertical Cylindrical Steel Welded Tank:

$$
h_{v}=1.67 \eta a R \text {. }
$$




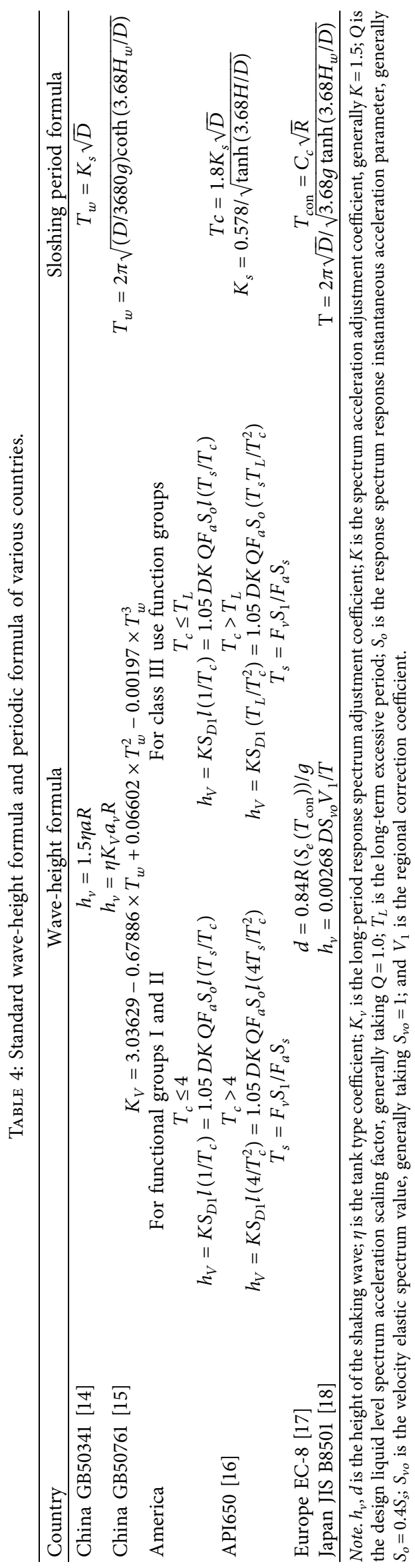




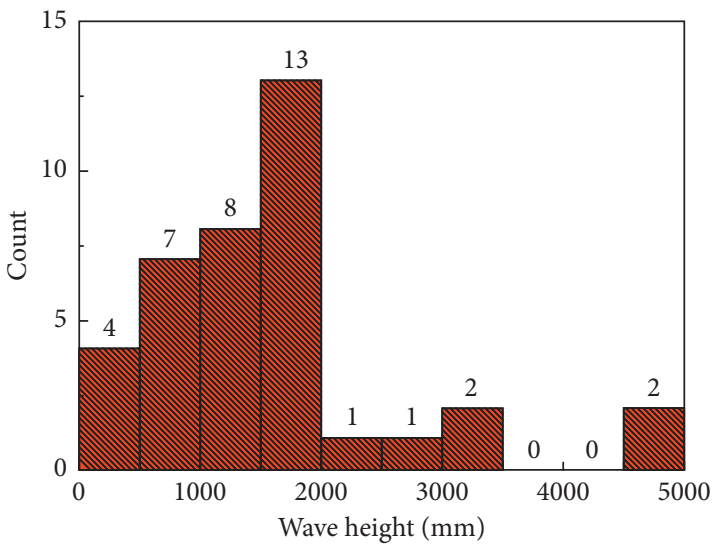

FIGURE 9: Simulated wave height distribution of near-fault ground motion.

TABLE 5: RMS and gauge wave heights of excitation wave heights for near-fault ground motions.

Vertical storage tank Root mean square value Mean value GB50341 computed wave height GB50761 computed wave height $\begin{array}{rrrrr}10,000 \mathrm{~m}^{3} & 1893 & 1611 & 1680 & 1067\end{array}$

GB50761-2018, Code for Seismic Design of Petrochemical Steel Equipment:

$$
\begin{aligned}
h_{v} & =\eta K_{V} a R, \\
K_{V} & =5.3868-1.2043 \times T_{w}+0.11712 \times T_{w}^{2}-0.003495 \times T_{w}^{3},
\end{aligned}
$$

where $\eta$ is the tank type coefficient; the floating roof tank is taken as 0.85 , the fixed top tank is taken as $1 ; a$ is the seismic influence coefficient of damping of $0.005 ; K_{v}$ is the longperiod adjustment coefficient; and the adjustment factor of this section is included.

\section{Conclusion}

On the basis of this study, we drew two main conclusions. First, it was evident from the shaking table test of the vertical storage tank that the wave height of long-period ground motion and near-fault ground motion excitation with rich long-period waveforms was larger. This wave-height value had a certain linear relationship with the peak acceleration of ground motion, and the ratio of two wave heights was approximately equal to the ratio of two accelerations. In addition, the finite element simulation of the model tank under the same ground motion action showed that the simulation wave height and the test wave height had a good fit, and the two could be mutually verified.

Second, it was possible to simulate the shaking of a $10,000 \mathrm{~m}^{3}$ large vertical storage tank under the action of a near-fault earthquake. We used the pulse period or predominant period as the ground motion parameter to characterize the wave height. Through comparison, we found that the envelope ratio of the wave height calculated according to tank specifications in China, the United States, Europe, Japan, and other countries to the near-fault ground motion excitation wave height was not high. Therefore, to achieve the near-fault ground motion, it was necessary to modify the wave-height formula. In addition, we proposed the RMS method to modify the wave-height formula of the Chinese code for long-period waveforms. We also adjusted the double-damping correction of the Chinese tank code GB 50341, which provides a reference method for the scientific design of near-fault ground motion in the engineering of wave-height design.

\section{Data Availability}

The data used to support the findings of this study are included within the article. The data used to support the findings of this study are available from the corresponding author upon request.

\section{Conflicts of Interest}

The authors declare that they have no conflicts of interest.

\section{References}

[1] S. J. Gang, Isolation of Large Vertical Storage Tank-Theory, Method, Test, Science Press, Beijing, China, 2009.

[2] C. L. Fu, Base Isolation and Sloshing Control of Large-scale LNG Storage Tanks, Dalian Maritime University, Dalian, China, 2012.

[3] S. J. Yan, Experimental Study about Dynamic Response of Unanchored Model Tank with Floating Roof under Lateral Earthquake Excitation, Zhejiang University, Hangzhou, China, 2012.

[4] Z. L. Jian, "Research and optimization of $15 \mathrm{~km}^{3}$ gas spherical tank design," World Earthquake Engineering, vol. 34, no. 2, pp. 190-199, 2018.

[5] J. D. Wang, D. Zhou, and W. Q. Liu, "Response of liquid in cylindrical tank with rigid annual baffle considering damping effect," Advances in Civil Engineering, vol. 255-260, pp. 3687-3691, 2011. 
[6] X. D. Cheng, J. J. Hu, and L. M. Zhao, "Dynamic response analysis of vertical cylindrical storage tanks based on ADINA," Advances in Civil Engineering, vol. 90-93, pp. 1482-1485, 2011.

[7] Z. L. Jian, "Study on sloshing wave height of large vertical storage tanks under long period earthquake," Journal of Natural Disasters, vol. 28, no. 3, pp. 87-95, 2019.

[8] Z. L. Jian, "Study on shock absorption performance of spherical tank with viscous damper," World Earthquake Engineering, vol. 35, no. 2, pp. 57-67, 2019.

[9] G. W. Housner, "Dynamic pressure on accelerated fluid containers," Bulletin of Seismological Society of America, vol. 47, no. 1, pp. 15-35, 1957.

[10] M. A. Haroun and G. W. Housner, Dyamic Interaction of Liquid Storage Tanks and Foundation Soil, Atlanta, Georgia, 1981.

[11] L. Hui, The Seismic Action Comparison Between Chinese, American, European and Japanese Seismic Design Codes for Buildings, Harbin Institute of Technology, Harbin, China, 2011.

[12] F. Li, "Comparison of seismic fortification aims and earthquake actions between eurocode 8 and Chinese seismic design code for buildings," Structural Engineers, vol. 12, pp. 22-26, 2006.

[13] J. Zhinan, The Evolution of Some Provisions in Chinese Seismic Code of Buildings and Comparison of these Provisions between Chinese and European Codes, Institute of Engineering Mechanics, China Seismological Bureau, Harbin, China, 2010.

[14] GB 50341-2014, Code for Design of Vertical Cylindrical Welded Steel Oil Tanks, Planning Publishing House, Beijing, China, 2014.

[15] GB 50761-2018, Standard for Seismic Design of Petrochemical Steel Equipment, Planning Publishing House, Beijing, China, 2018.

[16] American Petroleum Institute, API 650-2013 Welded Tanks for Oil Storage, AP Institute, Washington, DC, USA, 2013.

[17] Structural seismic design-silos, tanks and pipes, Eurocode 84, 2006.

[18] JIS B 8501-1995, Structure of Steel Welded Tank, JISC, Tokyo, Japan, 1997. 


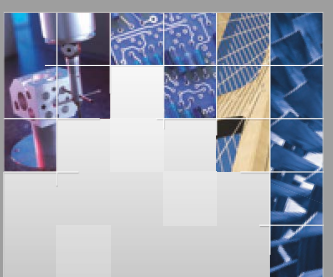

\section{Enfincering}
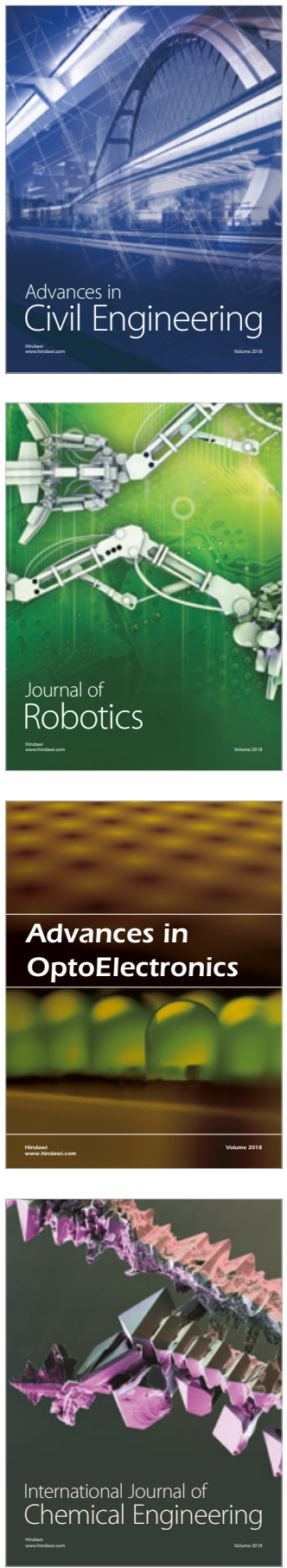

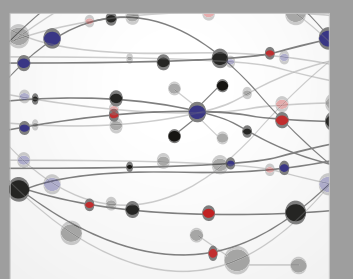

\section{Rotating \\ Machinery}

The Scientific World Journal

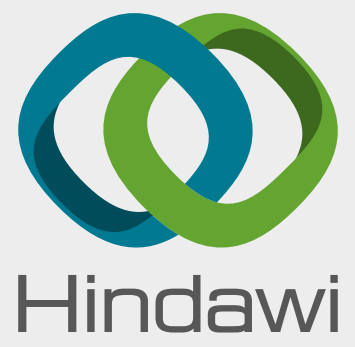

Submit your manuscripts at

www.hindawi.com
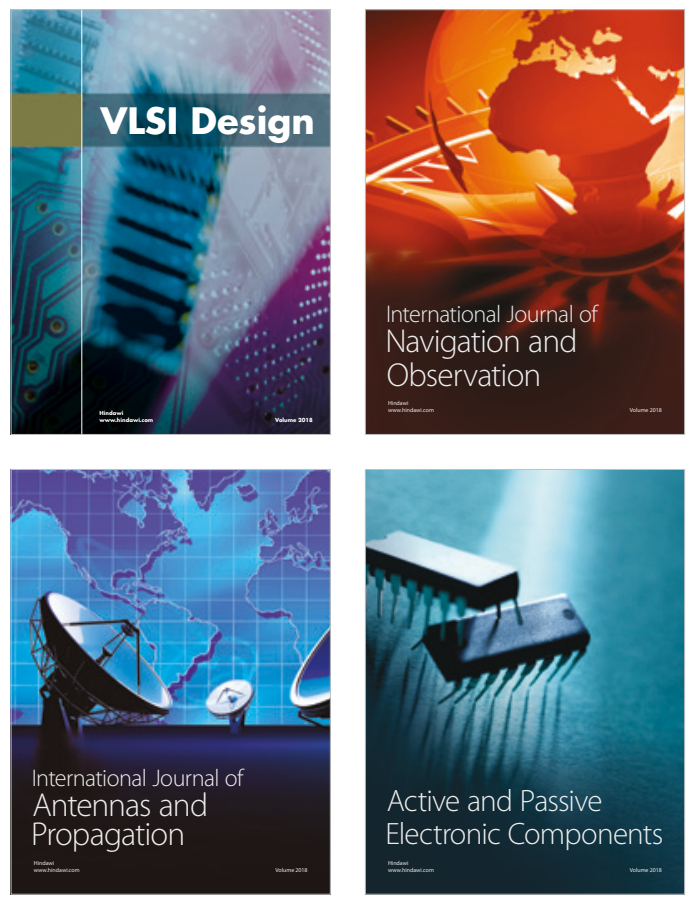
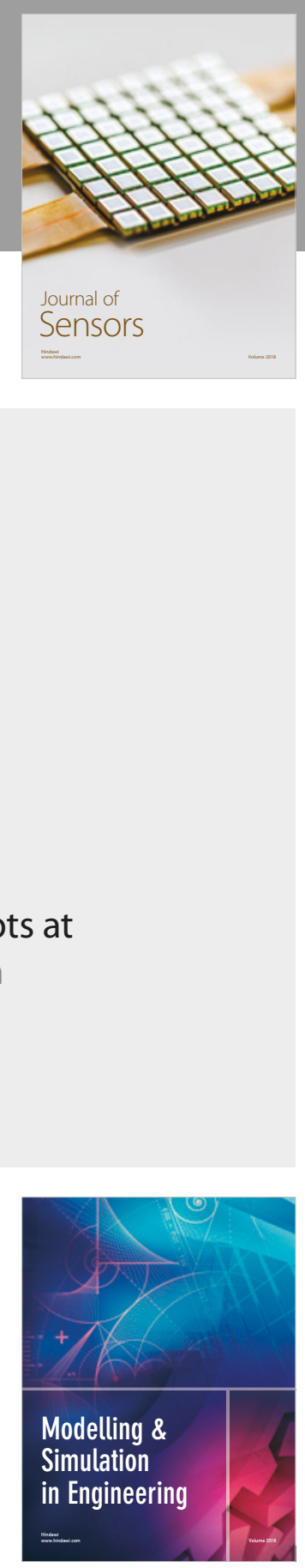

\section{Advances \\ Multimedia}
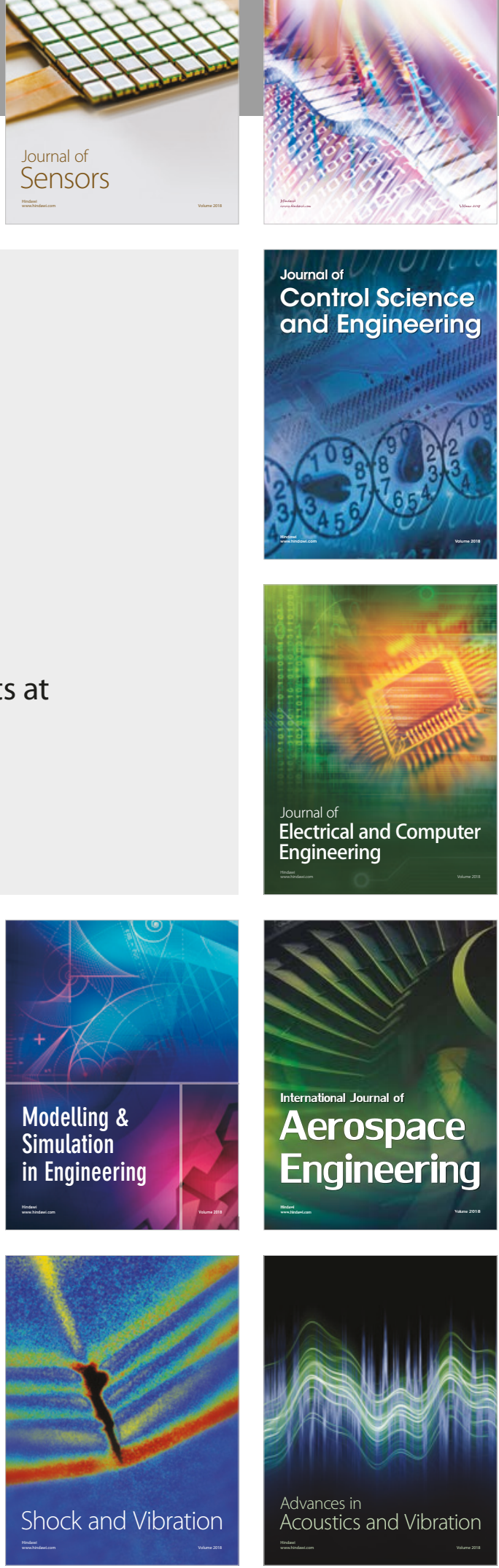